\title{
Parametric study on moment redistribution of fiber reinforced concrete continuous beams with basalt FRP bars
}

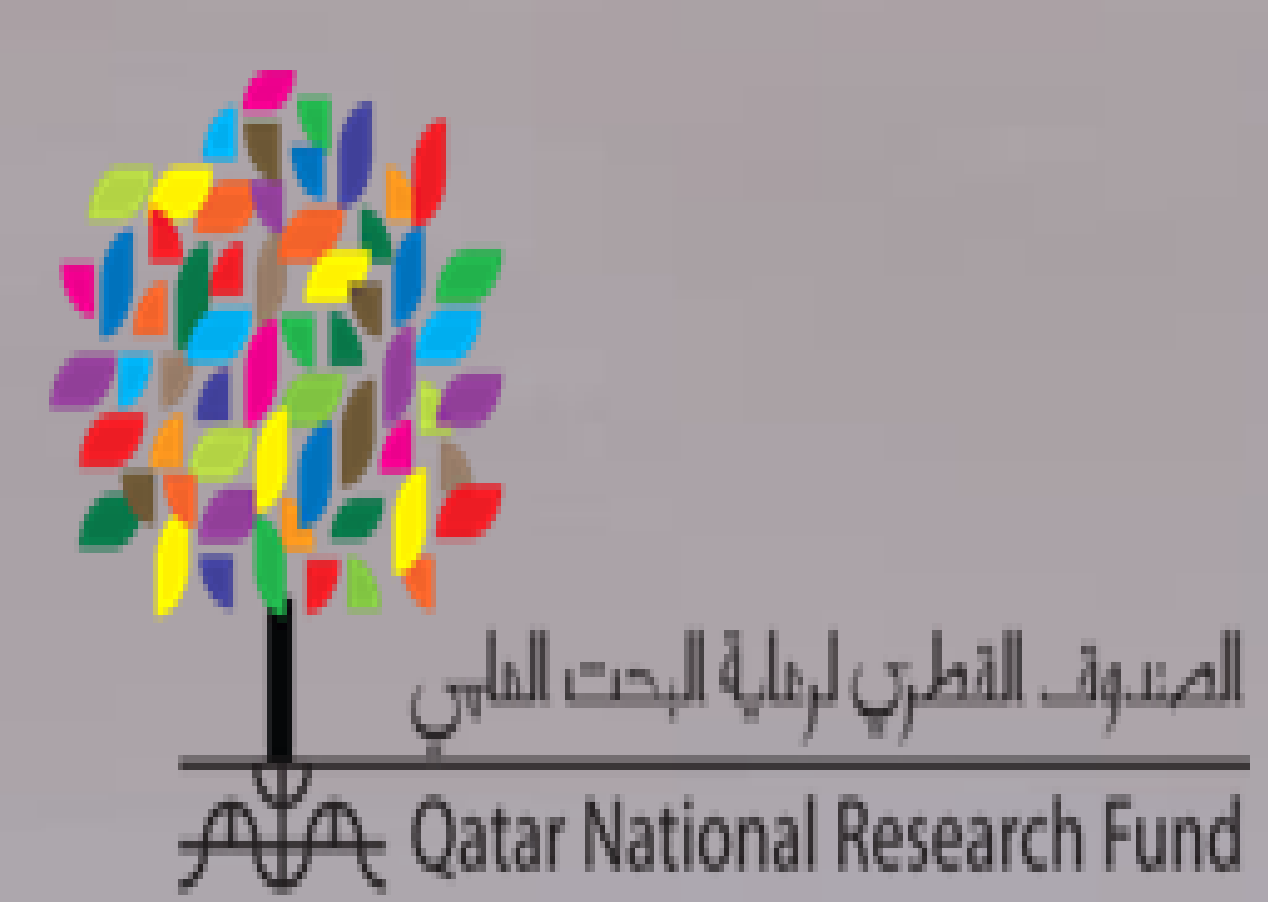

Graduate Students
cience and Engineering

\section{Background}

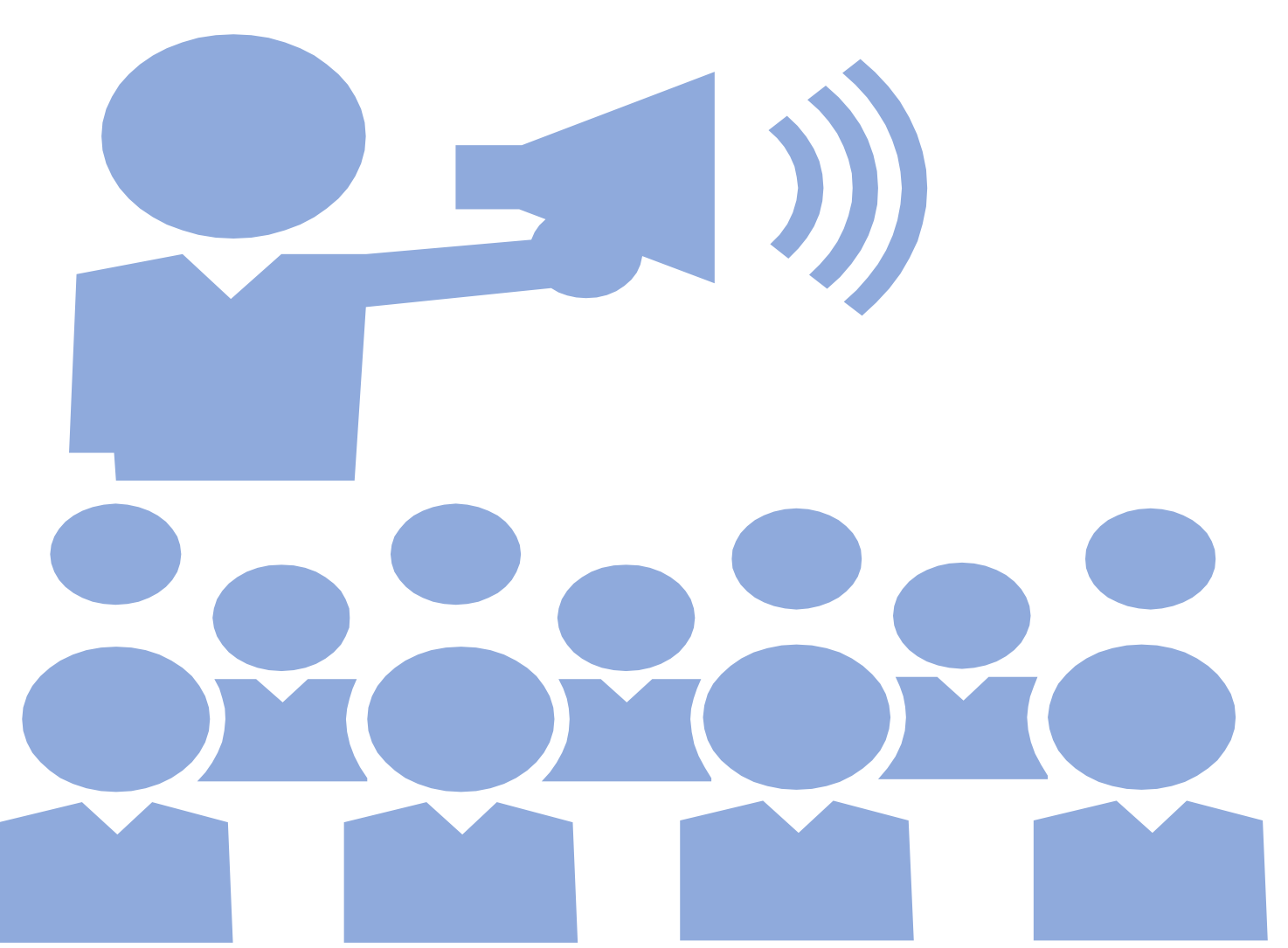

\section{Objective}
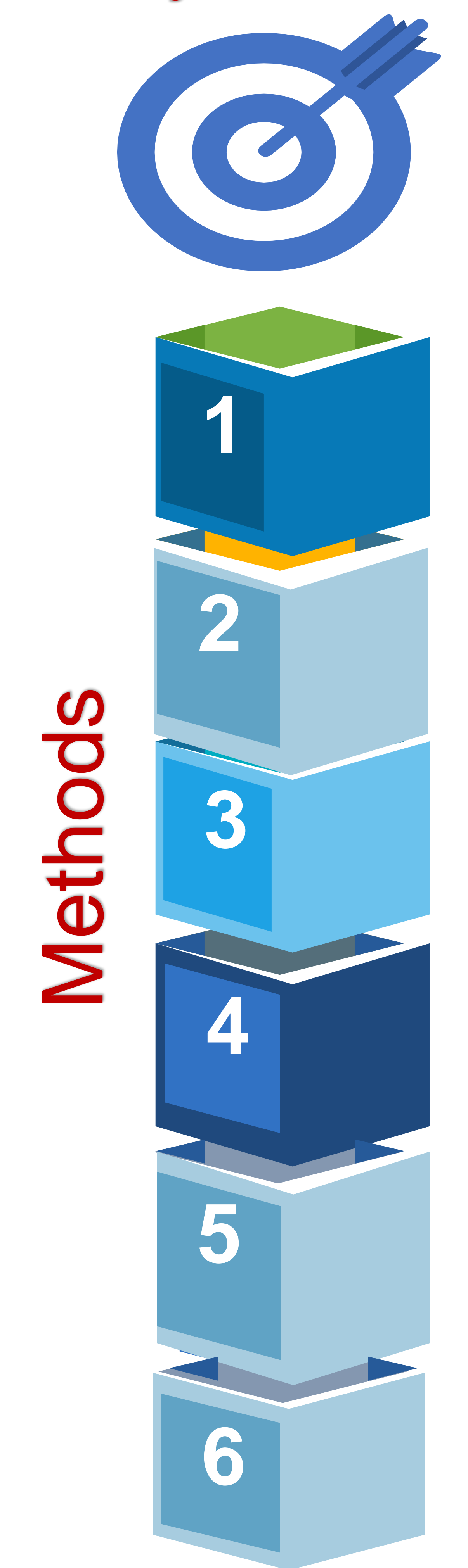
The experimental program consists of ten concrete
continuous beams over two spans of $1800 \mathrm{~mm}$ each and a rectangular cross-section of $200 \times 300 \mathrm{~mm}$

Different flexural reinforcement materials (steel and BFRP) with steel stirrups were considered

Different flexural reinforcement ratios (0.3-3.9pfb) were considered at both top and bottom sections to allow for moment redistribution of $0 \%$ to $20 \%$

Volume fractions of Basalt-macro fiber (BMF) of 0.75 and $1.5 \%$ were used to enhance the concrete shortcoming properties such as the tensile strength

A FEM modeling was conducted using ABAQUS software, release 14. The produced model was utilized to perform a parametric study on the tested beams

A linear regression analysis was performed using Minitab 17 software to generate a formula that predict moment redistribution

During loading, forces were transferred from the low-stiffness section to high-stiffness section. This behavior was observed in the beams that have higher bottom reinforcement

The ratio between bottom reinforcement to top reinforcement should be more than 0.3 to redistribute forces between the critical sections

$\%$ Moment redistribution $=3.72+0.444$ (volume fractions of BMF) +0.0212 stirrups spacing -0.02505 top reinforcement +0.04102 bottom reinforcement $\left(R^{2}=87.28 \%\right)$

\section{Conclusion}

This study is the first of its kind that evaluated the moment redistribution in continuous concrete beams with BFRP bars. Moment redistribution occurs in beams that have at least a ratio of bottom to top reinforcement of 0.3

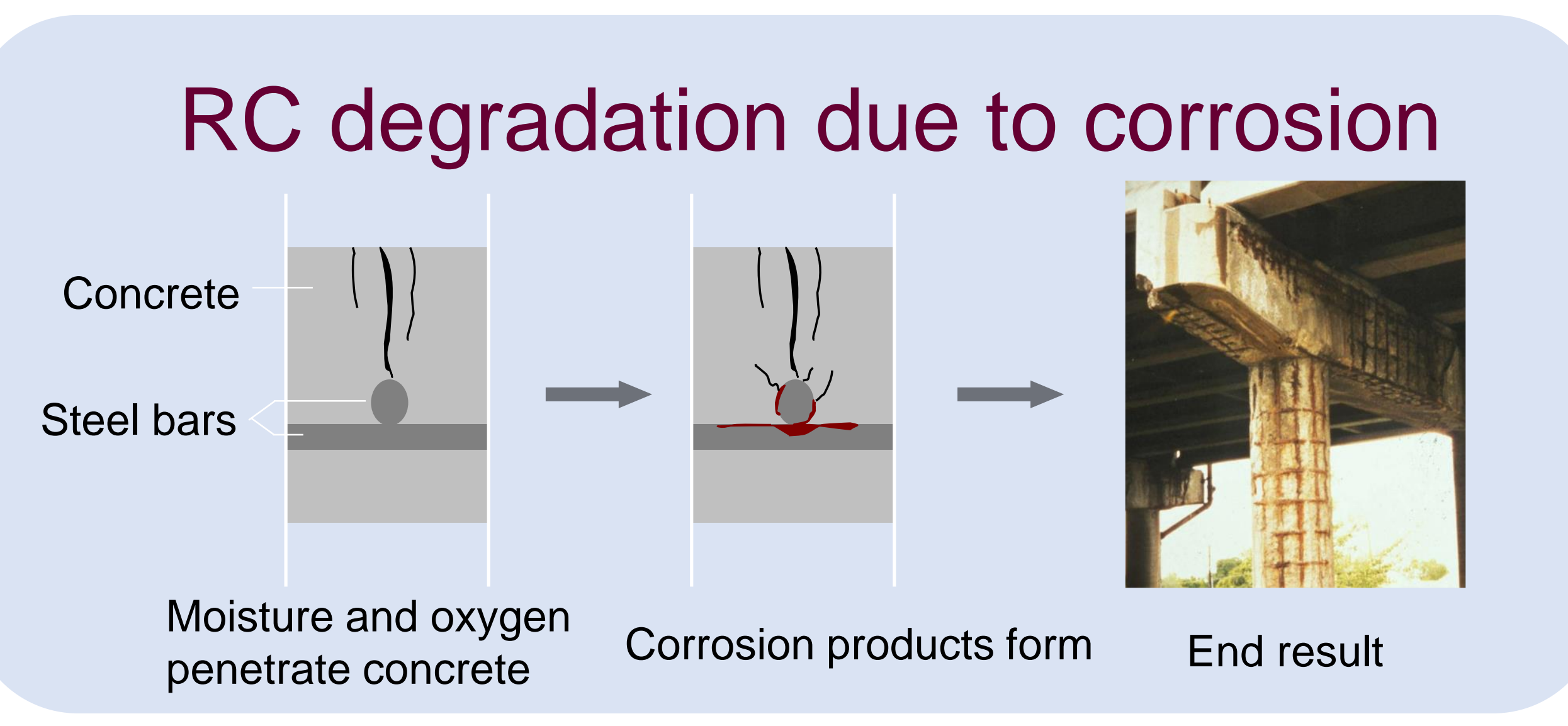

Moment redistribution enhances the ductility of continuous beams and reduce their congested rebar

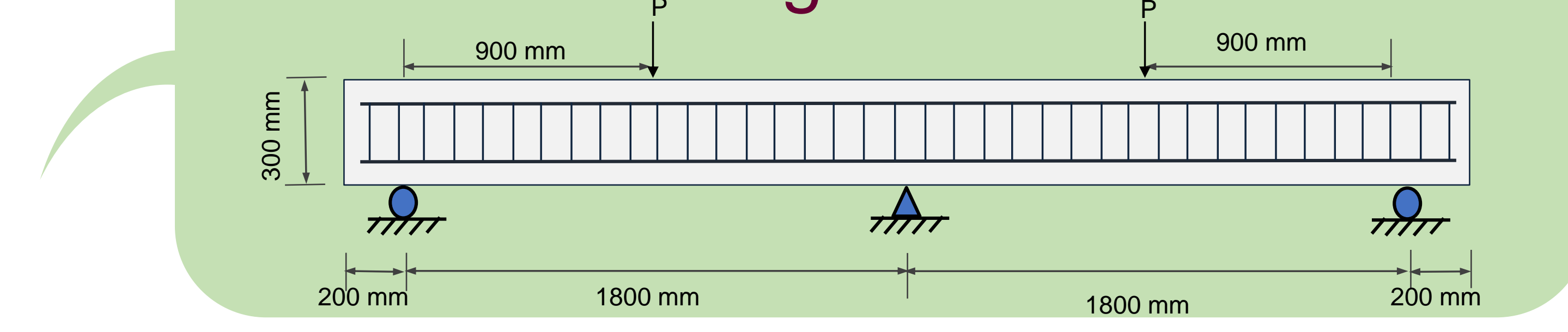

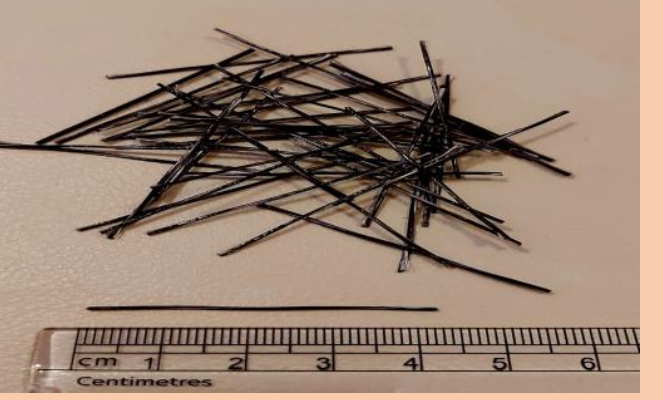

